\title{
Article
}

\section{Is Domestic Abuse an Adult Social Work Issue?}

Robbins, Rachel, Banks, Concetta, McLaughlin, Hugh, Bellamy, Claire and Thackray, Debbie

Available at http://clok.uclan.ac.uk/13917/

Robbins, Rachel ORCID: 0000-0002-6207-7703, Banks, Concetta, McLaughlin, Hugh, Bellamy, Claire and Thackray, Debbie (2016) Is Domestic Abuse an Adult Social Work Issue? Social Work Education, 35 (2). pp. 131-143. ISSN 0261-5479

It is advisable to refer to the publisher's version if you intend to cite from the work. http://dx.doi.org/10.1080/02615479.2016.1140733

For more information about UCLan's research in this area go to http://www.uclan.ac.uk/researchgroups/ and search for <name of research Group>.

For information about Research generally at UCLan please go to http://www.uclan.ac.uk/research/

All outputs in CLoK are protected by Intellectual Property Rights law, including Copyright law. Copyright, IPR and Moral Rights for the works on this site are retained by the individual authors and/or other copyright owners. Terms and conditions for use of this material are defined in the policies page.

\section{CLoK}

Central Lancashire online Knowledge www.clok.uclan.ac.uk

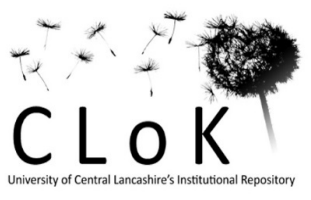




\section{Abstract}

Within a global profession with a stated definition that includes "promoting social change and development, social cohesion and the empowerment and liberation of people" (IFSW, 2014: online), it would be expected that the issue of domestic abuse would be integral to the training and role of all social workers. This article reports on research, which highlighted both a lack of understanding of the role of adult social worker within cases of domestic abuse and also a desire for further training around the issue. However, this article sets out how the current UK (in particular, English) context of social work marginalises the issue of domestic abuse within practice with adults. This marginalisation has been achieved through the construction of domestic abuse as a children and families issue and limited duties, powers and resources within statutory work to support victims/survivors in their own right, rather than as "failing" parents. However, the article argues that the role of social work education should be wider than teaching to the current policy or procedures and instead encourage a wider appreciation of the social, historical and political context. The article concludes with tentative suggestions for how domestic abuse could be considered within the social work curriculum for adult practitioners. This is in acknowledgement that social workers can be well positioned for the detection, investigation and support of those experiencing abuse.

\section{Introduction}

Services that offer support for adults and children victims, survivors and perpetrators of domestic abuse are provided by a range of statutory and voluntary agencies, in welfare, health, educational, legal and criminal justice settings. The aim of this paper is to establish whether within the current context of adult social work, domestic abuse can be considered an adult social work issue and if so, what this means for the social work curriculum. This discussion builds on findings from interviews with adult social workers as part of a research project examining the role of adult social care within MARACs (Multi Agency Risk Assessment Conferences tasked with the protection of adults and children within high risk domestic abuse situations).

In the UK, the Home Office (2013a, p2) provided the following definition of domestic abuse:

"...any incident or pattern of incidents of controlling, coercive or threatening behaviour, violence or abuse between those aged 16 or over who are or have been intimate partners or family members regardless of gender or sexuality"

This was a revision of previous definitions, to reflect an emphasis on patterns of coercive behaviour as particularly pertinent in domestic abuse. It also widens the definition to include the experiences of younger adults.

Defining domestic abuse is a useful first step in trying to establish the scale and prevalence of the phenomenon. There are long-rehearsed arguments about official figures and statistical data relating to domestic abuse. These arguments are linked to the acknowledgement of personal, private behaviours, their reporting and recording. These discussions are valuable and do not hide that the existing evidence points to domestic abuse as being widespread with findings broadly consistent across studies. In the UK, for example, in 2012, the Home Office (2013b) estimated that 1.2 million women suffered domestic abuse. Flatley et. al (2010) estimated $26.6 \%$ of women and $15.9 \%$ of men 
aged between 16-59 had experienced one or more forms of partner abuse. However, despite the evidence suggesting that domestic abuse is a common experience, it is often seen as a specialism within social care and work.

Feminist research and practice has been key to establishing the need to improve practice and research in relation to domestic abuse. Research in the UK of social services casefiles (Humphreys, 2000 and Maynard, 1985) demonstrated that until recently there was little recognition of consideration of violence towards mothers. However, lately a more direct link between domestic abuse and child abuse has emerged, with the potential damage of children witnessing domestic abuse acknowledged (Brandon and Lewis, 1996). This activity means that domestic abuse is now firmly mainstreamed into Child Protection practice as part of the 'toxic trio' (Ofsted, 2010) alongside mental health and substance misuse. It has also become part of the child protection legal framework with the new category of harm; 'impairment from seeing or hearing the ill-treatment of another' being introduced in the Child and Adoption Act of 2002. Although this is broadly welcomed it is not entirely unproblematic. The problem with constructing domestic abuse as primarily a child protection issue is highlighted in Peckover and Bridstone (2007), who suggest that the focus on child protection means that women are seen primarily as mothers rather than victims and the fathering role of perpetrators goes unexamined. The different histories and practices of those involved in working with families where domestic abuse is present is also highlighted in Hester's (2011) metaphor of Three Planets where she examines the potentially contradictory roles played by agencies working with adult victims, child protection agencies and the family courts. In effect, she suggests that this disconnected set of practices is producing 'culpable victims'. Alongside these concerns, there is the issue of how social work can respond to domestic abuse where children are not present and/or for women who have social care needs of their own. For example, Lazebblatt et al. (2013) in reviewing older women and domestic abuse note that older women are virtually absent from the research literature and that; 'service providers and policy makers often assume that DV stops at around 50,' ( Lazenblatt et al. 2013, p28). There was a stark demonstration of this in the Serious Case Review (Southend Safeguarding Adults Board) into the murder of 81 year old Mary Russell, which highlighted a lack of appreciation of risk in relation to domestic abuse and older people, in a case where a number of agencies, including social services, had been alerted to injuries.

This dilemma was exemplified within a research project undertaken looking at the role of adult social care within MARAC processes (McLaughlin, et.al., 2014 and Robbins et. al., 2014).

\section{Background}

A MARAC is a multi-agency information-sharing meeting concerned specifically with individual cases of domestic abuse identified as high-risk. The range of agencies represented is expected to include Criminal Justice Service agencies, health, housing, children services and other welfare agencies. This is in recognition that:

There is usually a wealth of information held in the community about all the people impacted by domestic violence in a particular household, but it takes MARAC type processes for that information to come together (Robinson, 2004, p15)

MARACs are focused on those cases considered to be at the highest risk of serious harm or domestic homicide, and therefore could include older adults, adults with physical, sensory or learning 
disabilities, mental health issues and/or those who abuse substances. In order to identify potential MARAC level cases, a Domestic Abuse, Stalking and 'Honour'-Based Violence Risk Identification Checklist is completed (DASH-RIC). Whilst the majority of forms are completed by the police, the DASH-RIC can be completed by GPs, Health Visitors, Housing Officers, Social Workers, etc. for referral into the MARAC. This form contains 24 risk factors which are ticked and the number of ticks against local thresholds will determine whether the case is discussed at a MARAC. Evaluation of MARACs have highlighted their importance in development of trust and understanding between agencies and improved information sharing (Robinson, 2004 and Steel et. al., 2013). However, this improvement was often based on personal commitment and with the work being seen as additional to current work (Robinson, 2004). Whilst risk assessment is a necessary part of the social work task and the use of decision-making tools provide structure to the task (Barlow et. al., 2012), Peckover (2014, p1778) has criticised the DASH-RIC approach as it privileges "actuarial-based decision making over professional judgement, and categorises cases which by their nature are complex and situated".

This paper is based on a research project entitled: to identify and assess the effectiveness of social care's contribution to the development of MARACs and the protection of adults facing domestic abuse. Practice within the field of domestic abuse does not reside with any one agency. The aim of the research was to clarify the role (if any) for social workers in adult social care. New guidance from NICE (2014) and the Local Government Association and the Association of Directors of Adult Social Services (LGA and ADASS, 2014) both highlight the role of health, social work and social care practitioners in the identification and support of those affected by domestic abuse. Yet the relationship between adult social work professionals who work to support service-users and identification of domestic abuse is under-researched. Heffernen et al. $(2012$, p13) notes:

Regardless of positive strides being made in acknowledging domestic violence as a global health issue, there remains a serious gap in research exploring social care intervention in cases of domestic violence.

The study received ethical permission from the National Institute of Social Care and Health Research. The research adopted a multi-methods case study (Cresswell, 2003) approach to a city in the North of England with above average MARAC referrals. The case study focused on just one city to allow the research team to focus in greater detail and depth on the operation of a single MARAC. The research data collection used a multi-methods approach and included all research team members attending a MARAC; interviewing 24 agency representatives who attended MARACS (plus some who did not, but were invited), 20 social workers in adult social care; focus groups with Independent Domestic Violence Advocates (IDVAs) and practitioners from Women's Aid. The team also interviewed 14 women whose cases had been considered by a MARAC. We then attempted to reinterview these service users after six months to offer a more reflective opportunity to consider the process, but we were only able to contact and re-interview four of the original cohort.

The data was analysed thematically using the constant comparative method (CCM) (Boeije, 2002) both within and between the various data sets. However, this paper will concentrate on the findings of the interviews of 20 social workers in adult social care.

Overall, the interviews suggested a lack of clarity about social work's role in domestic abuse. This was confirmed by senior social care managers who acknowledged that roles were unclear: 
"Domestic abuse is everyone's business'...I know it is very important that we're all around the table, but not all clear why we are there..I am embarrassed by department's response only three managers across the city as opposed to 15 in children's - makes it difficult to allocate time.... We need to think about where MARAC sits within the structure and where it fits into MASH (Multi-Agency Safeguarding Hubs) and we need to look at our admin systems and see if we could do it better." (Social Care Manager)

It is argued that this lack of clarity is an effect of contradictory policy and practice contexts and was echoed within the interviews with front-line practitioners outlined below.

\section{Research Design, Methods and Analysis}

Interviews were conducted with 20 social workers in an adult social care team, serving a central district of the case study city. All participants received an information sheet about the research and were asked to sign consent forms. As has become more common in "Austerity" UK, the team had recently widened its remit from exclusive work with adults aged 65 or over, to include working with any adult over 18 with a physical or sensory disability in receipt of community care services. The interviews were semi-structured with a core set of questions asked of all participants aimed at eliciting their understanding of domestic abuse, the MARAC process and how it could support work with vulnerable adults and their own training needs. The questions were devised following the literature review and were designed to further interrogate issues of MARAC efficiency. All the interviews were audio-recorded and transcribed and analysed within the research team, comprising of five researchers. Following Braun and Clarke's (2006) method for identifying, analysing and reporting patterns within data four key themes emerged from the interviews. These findings were taken to a team meeting of the social workers who had been interviewed for further discussion and clarification.

\section{Key Themes from the Research in relation to Adult Social Care Practice}

The first of the four themes was that there was a range of understanding and response to domestic abuse. From within the same team the two contrasting responses were received to questions about their understanding of the MARAC and the check list.

"I would mentally consider the MARAC process and the RIC and check some of the questions and would consider whether it would make a MARAC case"

“...isn't that a police role..."

Only eight (40\%) of the practitioners interviewed had knowledge of the MARAC processes. Most of the respondents could only provide piecemeal understandings of their specific agency role, whilst some practitioners could not identify domestic abuse as a social work issue. The process of the research highlighted this gap in some of the respondents' knowledge and the interviews offered an opportunity to explain and discuss MARAC with practitioners. The filling out of a DASH-RIC can facilitate immediate action for service-users at high risk and it is an important resource for social workers.

The second theme was the lack of a conceptual framework to support practice around domestic abuse and safeguarding. There was evident uncertainty of how to classify domestic abuse within 
practice and which route is best to take to protect service-users. Many of the social workers (n.13, $65 \%$ ) could identify recent examples of son/mother, grandson/grandmother abuse which they had encountered in their case load, further complicating the boundary of safeguarding, domestic abuse and the nature of domestic abuse perpetrators and settings. There have been attempts to address this blurring of boundaries between domestic abuse and safeguarding. The LGA and ADASS report (2013) noted that making connections between safeguarding and domestic abuse is a key area of development to be addressed. However, the two discourses have evolved as distinct and different. Responses to domestic abuse originally were local, informal and informed by second wave feminist activism. Safeguarding policy and practice, in contrast, has been a product of statutory work and informed by case-management and risk assessment. This difference is reflected in the vocabulary. Safeguarding uses terms such as financial abuse, sexual abuse or theft, fraud and assault. The emphasis is on the criminal or dishonest behaviours. However, domestic abuse uses terms such as victim, perpetrator and survivor concentrating on coercive and controlling behaviours, with an emphasis on power and intimacy. This leads to confused responses. Khalil (2013, online) argues that we need cohesive interventions as social work's lack of domestic abuse awareness fails vulnerable adults and that:

"Adult safeguarding professionals all too frequently try to manage domestic abuse referrals using social care interventions meaning the most effective option is missed."

However, the third theme identified was that of the complexity of issues of capacity, consent and the potential vulnerabilities of some service-users within domestic abuse cases. This is most aptly illustrated in the following quote from a social worker within the research:

If a customer has capacity, knows the consequences of their action, and doesn't consent to further action then you can't do anything, can't force the issue, can only advise and give what the options are.

This underlines some of the difficulties of addressing domestic abuse within the current statutory adult services social work relationship. If a person is seen primarily as a customer of social care services, addressing problems within the family or intimate relationships may appear to be out of the scope of statutory social work. Furthermore, if the service-user has been assessed as having capacity to make choices about their care, it leaves an apparent discomfort in addressing domestic abuse. The construction of the "customer" as having capacity to make choices ignores the wider impact and context of living with abuse. Further consideration is required as to how the agency of a traumatised or abused subject is constructed and can be appropriately considered and assessed within a context of abuse. Most worryingly this quote appears to condone inaction. It suggests the worker is caught in what Cohen (2001, p194) calls "the dynamics of knowing and not knowing" which becomes the "essence of denial and bystanding".

The fourth key theme was the issue of training. Training was expressed as a way to rectify the lack of understanding and all the respondents stated that they would welcome this. However, this was often within a discussion that also reflected concerns about caseloads and job boundaries. Any further training had to be able to demonstrate relevance and utility. Therefore, before the content of training can be addressed, it is important to acknowledge the current context and tensions within the provision of adult social care. 


\section{The Current Context of Adult Social Work}

Statutory agencies such as Community Mental Health Teams, Learning Disability Trusts, Adult Social Services and many voluntary, charity and private organisations employ qualified adult social workers. Social work is a profession that is charged with statutory duties regarding assessment, rationing of resources and managing risk. These duties are supported by professional registration and values which highlight anti-discriminatory practice and advocacy for the needs and rights of marginalised people. The relationship between adult services and domestic abuse has long-been contentious (DH, 1995). However, recent events have meant that social care for adults has emerged as a separate and distinct area of service provision in England after the separation of children's services in 2006 replacing the general terms of community care and personal social services (DH, 2006). The result of this is that domestic abuse work has gone under the radar within adult social care as it has become subsumed within children and families social work.

Underpinning the practice of social work with adults is the Knowledge and Skills Statement for Social Workers in Adult Services (DH, 2015). This document sets out the minimum requirements for adult social workers in England at the point of completion of their Assessed and Supported Year in Employment (ASYE). The document makes links with the global definition of social work and the role of the social worker in promoting "social change and development, social cohesion and the empowerment and liberation of people" (IFSW, 2014, online). Whilst domestic abuse is not specifically referenced within the statement, it does make links between well-being and issues of poverty, inequality and functioning of families which have relevance. The emphasis in terms of practice is on person-centred practice, safeguarding, mental capacity and direct work in providing clear assessments of need.

A further shift for adult social workers within England has been the introduction of the Care Act (2014). The Care Act consolidates, streamlines and codifies over sixty years of piecemeal legislation in adult social work. It brings together the Law Commission's recommendations on Adult Social Care and the changes suggested by the Dilnot Commission on funding of care and support. The Act places particular emphasis on the principle of 'well-being'. The Care Act's definition of well-being acknowledges that this relates to domestic, family and personal relationships, as well as protection from abuse and neglect, but again makes no specific reference to domestic abuse. The Care Act is supported by guidance to support implementation. The Act was supposedly drafted with the ideals of placing the service-user in control. However, the guidance has been critiqued for retaining the status quo and undermining the principles (Slasberg and Beresford, 2014). The guidance (DH, 2001) to the Care Act makes specific mention of domestic abuse, recognising it as a category of abuse. However, the safeguarding duty only applies to an adult who is already eligible for services and many victims of domestic abuse are therefore unlikely to qualify for statutory support simply on the basis of the experience of domestic abuse. This adds to the perception that domestic abuse falls outside of the remit of statutory social work unless the adult concerned is also deemed to be an 'adult at risk' i.e. that there are additional complicating factors such as mental health issues, substances misuse or a lack of capacity.

This lack of clarity of the role of adult social work is heightened within a context of tightening resources and higher thresholds for accessing adult social care (Glasby et. al, 2015). In particular, specialist services for domestic abuse have been targeted by local authorities in the bid for welfare 
savings. Towers and Walby (2012) assert that Local Authority funding for domestic abuse services was cut by $31 \%$ in $2010-2011$ and the indications are that this level of under-funding will continue. Within this policy and funding context, victims of domestic abuse are frequently constructed as agentic, free to leave abusive relationships (Hester, 2011). This perception of victims is problematic as research has shown that there are numerous barriers to leaving abusive relationships including poverty, homelessness, cultural/religious issues, immigration status, lack of protection from racism for minoritised women, disability, isolation, loneliness, fear and a lack of appropriate services (Burman and Chantler, 2005; Chantler, 2006; Hague et al, 2007; Walby, 2004). Further, leaving an abusive relationship does not guarantee freedom from abuse, as the victims' risk is heightened upon leaving abusive relationships and domestic abuse often continues even after the victim has left the abusive relationship (Bostock et al, 2009; Humphreys and Thiara, 2003; ONS 2013; Stanley et al 2011; Walby and Allen, 2004). The proliferation of new forms of technology has made it easier for perpetrators to continue to stalk and harass their partners or ex-partners via mobile phones and social media. In sum, these barriers constrain victims' opportunities to exercise freedom and control in their lives. There are also elevated risks to mental health arising from domestic abuse (Howard, 2012) and many of the barriers to leaving abusive relationships are in themselves known risk factors for the onset and maintenance of poor mental health (McManus et al, 2009).

In summary, to add to the lack of clarity, domestic abuse is contradictory. It can be seen both as outside the scope of statutory intervention and as a reason for social work support. Domestic abuse is unlikely to fall solely within the remit of social work and would entail working alongside other agencies. However, it should be noted that a narrow focus on current policy "produces a practitioner with the knowledge to follow procedure, but not the critical awareness that sees when the service outcomes are at odds with political objectives or who fails to infuse the policy framework with professional values" (Gregory and Holloway, 2005, pp618 - 619). Therefore, social work education should seek to educate beyond current conditions and constraints of practice, to protect what the profession wants to be and against losing an understanding of depth and breadth of complexity. It is with this in mind that a tentative curriculum for adult social work practice concerning domestic abuse is offered.

\section{Domestic Abuse and the Adult Social Work Curriculum}

Domestic abuse already appears as part of the curriculum of social work qualifying programmes. It can be addressed in modules concerned with practice interventions, human growth and development, and sociology or social policy. This paper is particularly concerned with addressing concerns of practitioner education both through ASYE and as part of Continuing Professional Development (CPD), primarily in academic settings but could be adjusted for in-house training, to address perceived gaps in knowledge in relation to domestic abuse within adult services in safeguarding. This is in acknowledgement that given the access to personal lives of marginalised groups, social workers may be well placed to identify, investigate and support those experiencing domestic abuse. However, this is tempered with an understanding that this could not be the sole charge of a social worker within statutory practice and that further advice and expertise should be sought from specialist agencies. It is hoped that the ideas suggested here are not seen as a template, but a starting point for further discussions and ideas. 
Social work education can be envisioned as being centred on the three overlapping areas of values, knowledge and skills. From a values perspective, any training in relation to domestic abuse needs to start from an acknowledgement that it is a widespread phenomenon and common experience. Social workers will not be immune and educators need to be aware that there will be survivors and even potentially those experiencing on-going domestic abuse within a classroom. Social workers are not immune from domestic abuse. This poses particular difficulties for educators and students. Preparation should include how to deal with disclosure whether within the group or separately to the educator. There should also be some input on ground rules and values that can minimise the potential of 'victim-blaming' discourses. However, the unacknowledged problem of domestic abuse within a classroom is how experiences shape knowledge and can produce resistance to the introduction of different theoretical positions. The classroom needs to provide a safe space to evaluate survivors own stories whether disclosed or not (Robbins, 2014).

The domain of knowledge is no less contentious. Sessions need to start with a common definition of domestic abuse. Most domestic abuse training highlights the extent of the problem, demonstrating that though domestic abuse can impact on men, women and children it is a gendered problem with violence against women linked to wider gender inequality (Falb et. al., 2015). The curriculum should also evaluate research that highlights problems for specific groups, especially those potentially in receipt of welfare services, such as women with learning disabilities. For example, Walter-Brice et al. (2012) found that women with learning disabilities in their study experienced marginalisation and oppression despite evidence from research that demonstrates women with disabilities are more likely to experience domestic abuse than women without disabilities. In addition, the type of abuse experienced is marginalised through the learning disability label, which can lead to ignoring women's issues and individual needs. Furthermore, there are unique forms of abuse experienced by women with disabilities who unlike their non-disabled counterparts are often dependent upon others to meet their healthcare and social needs. Examples of withholding medication or removing batteries from wheelchairs are demonstrated in literature (Hassouneh- Phillips and Curry 2002).

However, the concern here is that the raising of awareness of a problem against a context of increasing caseloads and reducing services could be perceived as unnecessary and prove counterproductive. Educators should also have knowledge of local agencies for referral. This again makes the point that domestic abuse is not the sole remit of social workers. This needs to be addressed through both improved knowledge and a consideration of the skills social workers already use. In terms of knowledge, educators could compile with students and practitioners a list of key local personnel in criminal justice, the IDVA (Independent Domestic Violence Advocate) service, housing and voluntary sector providers like Women's Aid.

In terms of skills, sessions should emphasise that the skills required in cases of domestic abuse relate to general social work skills, such as advocacy, person-centred care and risk assessment. Risk assessment is supported by the use of the DASH-RIC (which can be accessed through the Safe Lives website http://www.safelives.org.uk/). Practitioners should become familiar with the DASH-RIC which would promote understanding of the particular behaviours and situations which produce highly dangerous situations for some service-users. Practitioners also need to be aware that the thresholds for MARAC are high and time allocated to cases is limited. In the research identified above this amounted to 10 minutes per case (McLaughlin et. al., 2014). It would be impractical to simply increase the number of referrals to MARAC, especially if the assessment does not reflect an 
accurate picture of risk of significant harm or homicide. An inappropriate referral to MARAC will not support a service-user or improve their lives (Robbins et. al, 2014). Therefore, a fuller discussion of the role of risk within social work practice and assessment is required. This can start with the philosophical discussions of Giddens (1990) and Beck (1992) to the humanist stance of Payne (2011) with the emphasis on enabling security. Discussion should be research-based and acknowledge that good social work practice is a blend of promoting positive risk-assessment, situational responses and actuarial approaches (Dixon and Robb, 2015).

In order to link local knowledge and risk assessment skills, practitioners need to explore multiagency working. A facilitator could use the experience in the room to explore the strengths and barriers (including resource issues at a time of 'austerity') to effective multi-agency working in complex cases. However, this is where the problems of lack of clarity of role would be most apparent as "collaboration is improved when each agency has full knowledge of its arena" (French and Swain, 2012, p108). Social workers need to focus on the concept of well-being, especially in cases where consent and capacity issues are present. The presence of domestic abuse asks the practitioner to hold contradictory notions of the service-user as both autonomous and independent and at the same time as someone who may require assistance to which they cannot consent. Current legislation does not fully address and include this issue. Therefore, within discussions there would need to be a focus on accountability and responsibility. Domestic abuse is a safeguarding issue and practitioners should be aware of the potential to use both MARAC and local safeguarding protocols in parallel. Practice should not be forced into one system over the other.

However, no curriculum considering the issue of domestic abuse should ignore the impact of emotions within work. Taking the lead from Ferguson's (2005) discussion of child protection following Victoria Climbié's death, attention needs to be paid to the responses to working with discomfort and fear. Working with abuse is fearful work. The dominant response to this fear has

"been a rational-bureaucratic one of developing the law, procedures and performance management... Social work education has compounded this neglect with its emphasis on rights, empowerment and anti-oppressive practice to the exclusion of a more grounded analysis of the complexities of service-users, especially the challenges of working with resistant and often hostile people who do not want a service" (Ferguson, 2005: 782).

There are three suggestions here to support an understanding of risk, emotion and complexity when working with domestic abuse. The first is to use first-person accounts of victim-survivors of domestic abuse and to ensure that their voice is a part of the educational space. (A voice that is marginalised within MARAC processes, (McLaughlin et. al., 2014). Service-user involvement within social work is a democratic approach and the expertise and reflections on experiences of services received or needed could support understanding. Alongside this, educators can work with Domestic Homicide Reviews (DHRs) to consider the ways in which abuse falls through the gaps, considering not just the administrative and legal powers, but also the psycho-social dimensions of the work. The third suggestion is to incorporate how to work with perpetrators as well as victim-survivors. Morran (2008) has considered the negative potentially traumatic impacts of working with domestic abuse perpetrators. Mahon et. al., (2009) have highlighted how such work is concerned with the difficulties of bridging understandings of structural gendered inequalities and individual rights of 
perpetrators. All three suggestions should highlight the role of professionals remaining researchminded to inform their practice and analysis appropriately.

Finally, a key finding from the research into MARAC was that most MARAC attendees felt unsupported by their employers and supervisors whilst engaged with this demanding work (McLaughlin et. al., 2014). One MARAC attendee reported:

"I think it has changed me as a person, I think. You know, all I hear is the horror that people do to each other and I think it has changed me as a person. I think it can make you look at things more negatively."

Attention within the space of social work education needs to be paid to social workers' exposure to violence and threat, and the use of supervision, especially within a climate that places managerial concerns over professional practice (Mahon, 2008).

\section{Conclusions}

This paper has highlighted that the role of social work within adult social care and domestic abuse is contestable and complex. The current policy and practice contexts produce contradictory positions. Adult social work law does not address domestic abuse except where other additional risks or complicating factors such as disability are present. The practice environment, however, means that as funding and front-line services for domestic abuse are cut, the barriers for disclosing and leaving abusive relationships increase, so that needs and vulnerability of service-users can also increase. Adult social workers are well placed to detect and offer support to those experiencing abuse, but are not resourced or equipped to do so. Against this background, a tentative curriculum is suggested for social workers within adult social care that draws attention to the wider context of abuse and looks to effective multi-agency working as a key tool in addressing adult safeguarding where domestic abuse is present.

However, the complexity of the situation should not deter social workers from engaging with the issue of domestic abuse. Sensitive assessment skills can help to redress some of the problems victims of abuse face, as the following quote illustrates:

"Doing that risk assessment that day shocked me... It was there in black and white in front of me and it was wrong and I knew it was wrong... What I was going through wasn't right."

This quote was taken from an interview with a woman who had been supported through a period of domestic abuse. The risk assessment she is talking about is the DASH-RIC. Sensitive assessment can be liberating for the service-user. A greater understanding of processes and policy will support practice. However, any curriculum development around domestic abuse should also recognise the role of emotions and the need for support.

Adult social work and the relationship with domestic abuse is evolving, but threatened by the continuing impact of 'austerity' on a vulnerable workforce and service-user groups. However, to provide a healthier future the adult social workforce need to pay attention to the construction of domestic abuse, safeguarding and capacity to provide an ethical underpinning for future provision.

\section{Acknowledgements}


This presentation presents independent research commissioned by the NIHR SSCR. The views expressed are those of the author and not necessarily those of the NIHR SSCR or the DH, NIHR or NHS

\section{References}

Barlow, J., Fisher, J. D., and Jones, D. (2012) Systematic Review of Models of Analysing Significant Harm DfE

(https://www.gov.uk/government/uploads/system/uploads/attachment data/file/183949/DFERR199.pdf) [accessed 15 October 2015]

Beck, U. (1992) Risk Society: Towards a new modernity London: Sage

Boeije, H. (2002) "A purposeful approach to the constant comparative methods in the analysis of qualitative interviews' Quantity and Quality36, pp29-41

Bostock, J., Plumpton, M. and Pratt, R. (2009) 'Domestic violence against women: Understanding social processes and women's experiences' Journal of Community \& Applied Social Psychology 19, pp. 95-110.

Brandon, M. and Lewis, A. (1996) “Significant Harm and Children's Experiences of Domestic Violence" Child and Family Social Work 1, pp 33-42

Braun, V. and Clark, V. (2006) "Using thematic analysis in psychology" Qualitative Research in Psychology, 3, pp77-101

Burman, E. and Chantler, K. (2005) 'Domestic Violence and Minoritisation: legal and policy barriers facing minoritised women leaving violent relationships', International Journal of Law and Psychiatry, 28 , pp. $59-74$

Chantler, K. (2006) 'Independence, dependency and inter-dependence: struggles and resistances of minoritised women within and on leaving violent relationships', Feminist Review, 82, pp27 -49

Cohen, S. (2001) States of Denial: Knowing about Atrocities and Suffering Cambridge: Polity Cresswell, J. W. (2013) Research Design: Qualitative, Quantitative and Mixed Methods Approaches London: Sage

DH (1995) Abuse of older people in domestic settings: a report on two SSI seminars. DH, London DH (2006) Our Health, Our Care, Our Say: A new direction for community services London: HMSO DH (2014) Care and Support Statutory Guidance: Issued under the Care Act 2014 London: Department of Health

DH (2015) Knowledge and Skills Statements for Social Workers in Adult Services London: Department of Health 
Dixon, J. and Robb, M. (2015) Working with Women with a Learning Disability Experiencing Domestic Abuse: How social workers can negotiate competing definitions of risk British Journal of Social Work (Advanced Access)

Falb, K. L., Annan, J. and Gupta, J. (2015) Achieving gender equality to reduce inter-personal violence against women The Lancet: Global Health 3, pp302-303

Ferguson, H. (2005) Working with violence, the emotions and the psycho-social dynamics of child protection: Reflections on the Victoria Climbié Case Social Work Education 24, pp781 - 795

Flatley, J., Kershaw, C., Smith, K., Chaplin, R. and Moon, D. (eds.) (2010) Crime in England and Wales (2009 - 2010): Findings from the British Crime Survey and Police Recorded Crime Home Office Statistical Bulletin 12/10, London: Home Office

Giddens, A. (1990) The Consequences of Modernity Cambridge: Polity Press

Glasby, J., Miller, R., and Needham, C. (2015) “Adult Social Care” in L. Foster, A. Brunton, C. Deeming and T. Haux (eds.) In Defence of Welfare 2 Bristol: Policy Press

Gregory, M. and Holloway, M. (2005) "The Debate as a Pedagogic Tool in Social Policy for Social Students" Social Work Education 24, pp617-637

Hague.G., Thiara.R., Magowan.P and Mullender.A. (2007) Making the links, Disabled women and domestic violence, Final report. Bristol: Women's Aid

Hassouneh-Phillips, D., \& Curry, M. (2002), 'Abuse of women with disabilities: State of the Science' Rehabilitation Counselling Bulletin 45, pp96-104

Heffernen, K. Blythe, B. and Nicolson, P. (2012), 'How do social workers understand and respond to domestic violence and relate this to organisational policy and practice' International Social Work [published on-line 1 November 2012] pp1-22

Hester, M. (2011) The Three Planet Model: Towards an Understanding of Contradictions in Approaches to Women and Children's Safety in Contexts of Domestic Violence British Journal of Social Work 41, pp837-853

Home Office (2013a), Information for Local Areas on the Change to the Definition of Domestic Violence and Abuse London: Home Office

Home Office (2013b), Policy: Ending Violence against Women and Girls in the UK published 26 March 2013 https://www.gov.uk/government/policies/ending-violence-against-women-and-girls-in-the-uk

Howard, L. M. (2012), 'Domestic Violence: Its relevance to Psychiatry' Advances in Psychiatric Treatment 18, pp129-136

Humphreys C. and Thiara R.K. (2003) ‘Neither justice nor protection: women's experiences of postseparation violence', Journal of Social Welfare and Family Law, 25, pp. 195-214

Humphreys, C. (2000) Social Work, Domestic Violence and Child Protection Bristol: The Policy Press 
IFSW (2014) Global Definition of Social Work http://ifsw.org/policies/definition-of-social-work/

Khalil, S. (2013) How social workers' lack of domestic abuse awareness fails vulnerable adults Community Care http://www.communitycare.co.uk/2013/06/07/how-social-workers-lack-ofdomestic-abuse-awareness-fails-vulnerable-adults/

Lazenbatt, A.; Devaney, J.; and Gildea, A. (2013) Older women living and coping with domestic violence, Community Practitioner, 86, pp. 28-35

LGA and ADASS (2014) Adult Safeguarding and Domestic Abuse: A Guide to Support Practitioners and Managers London: LGA

Mahon, M., Devaney, J. and Lazenbatt, A. (2009) "The Role of Theory in Promoting Social Work Values and its Potential Effect on Outcomes in Work with Domestically Violent Men" Irish Probation Journal 6, pp151 - 170

Maynard, M. (1985) "The response of social workers to domestic violence" in J. Pahl (ed.) Private Violence and Public Policy London: Routledge, pp125 - 140

McLaughlin, H., Banks, C., Bellamy, C., Robbins, R., and Thackray, D. (2014) Domestic Violence, Adult Social Care and MARACs: Implications for Practice NIHR School for Social Care Research http://www.sscr.nihr.ac.uk/PDF/Findings/RF44.pdf

McManus S, Meltzer H, Brugha T, et al. Adult Psychiatric Morbidity in England, 2007: Results of a Household Survey. Health and Social Information Centre, Social Care Statistics, London, 2009

Morran, D. (2008), 'Firing Up and Burning Out: The Personal and Professional Impact of Working in Domestic Violence Offender Programmes', Probation Journal, 55, pp. 139-152

NICE (2014) Domestic Violence and Abuse: How health services, social care and the organisations they work with can respond effectively London: NICE

Ofsted (2010) Learning Lessons from serious case reviews 2009 - 2010 Manchester: Ofsted ONS (2013) Focus on: Violent Crime and Sexual Offences, 2011/12, Accessed 14/05/2015

Payne, M. (2011) Humanistic Social Work: Core Principles in Practice Basingstoke: Palgrave Macmillan

Peckover, S. (2014) Domestic Abuse, safeguarding children and public health: Towards an analysis of discursive forms and surveillant techniques in contemporary UK policy and practice British Journal of Social Work 44, pp1770 - 1787

Peckover, S. and Featherstone, B. (2007) Letting them get away with it: Fathers, Domestic Violence and Child Welfare Critical Social Policy 27, pp181-202

Robbins, R. (2014) "She knew what was coming": Knowledge and Domestic Violence in Social Work Education Social Work Education 33, pp917 - 929 
Robbins, R., McLaughlin, H., Banks, C., Bellamy, C. \& Thackray, D. (2014) Domestic violence and multiagency risk assessment conferences (MARACs): a scoping review, The Journal of Adult Protection, 16, pp389- 398

Robinson, A. (2004), Domestic Violence, MARACs for very high-risk victims in Cardiff, Wales: A Process and Outcome Evaluation Cardiff: University of Cardiff

Slasberg, C. and Beresford, P. (2014) Government Guidance for the Care Act: undermining ambitions for change? Disability and Society 29, pp1677 - 1682

Stanley, N., Miller, P., Richardson-Foster, H. and Thomson, G. (2011) A Stop-Start Response: Social Services' Interventions with Children and Families Notified Following Domestic Violence Incidents. British Journal of Social Work, 41, pp296-313

Steel, N., Blakeborough, L. and Nicholas, S. (2011), Supporting High-Risk Victims of Domestic Violence: A Review of Multi-Agency Risk Assessment Conferences (MARACs) London: Home Office Towers, J. and Walby, S. (2012) Measuring the impact in cuts in public expenditure on the provision of services to prevent violence against women and girls Report for Northern Rock Foundation and Trust for London

Walby S and Allen J. (2004) Domestic violence, sexual assault and stalking: finding from the British Crime Survey. Home Office Research Study 276. London: Home Office

Walby, S. (2004) The Cost of Domestic Violence. London: Women and Equality Unit

Walter-Brice, A., Cox, R., Priest, H. and Thompson, F. (2012), 'What do women with learning disabilities say about their experiences of domestic abuse within the context of their intimate partner relationships' Disability and Society 27, pp $503-517$ 